\title{
Stability Enhancement by Comparative Analysis of AI Techniques in Power System Stablizer Integrated With Hybrid System
}

\author{
Harsh Vardhan Singh \\ M. Tech. Scholar \\ Oriental College of Technology \\ Bhopal, India \\ hvsingh93@gmail.com
}

\author{
Dr. Ranjeeta Khare \\ Professor \\ Oriental College of Technology \\ Bhopal, India \\ rkhare18@gmail.com
}

\begin{abstract}
Hybrid system has been modeled in MATLAB/SIMULINK environment which is then integrated with two generators based power system. The work has done over analysis of THD level in voltage output from the hybrid system with various controls being proposed for the power system stabilizer. Various controls like PI-Hysteresis, particle swarm optimization (PSO) and PSO with neural network (NN) have been implemented for comparative study. It was found that the distortion level in voltage output waveform was least in stabilizer having PSO-NN control which is $3.36 \%$. Also the active power enhancement reached a whooping value of $9.4 \mathrm{KW}$ from the hybrid system.
\end{abstract}

Keywords: Hybrid system, Stabilizer, Particle swarm optimization, neural network, Hysteresis control.

\section{INTRODUCTION}

Hybrid Renewable Energy System is a term to describe the combination of two or more renewable and nonrenewable energy sources. Basic components of such systems are power sources (wind turbine, diesel engine generator and solar arrays), the battery and the power management center, which regulates power production from each of the sources [1]. Micro grid is an integrated energy system that includes energy resources, loads and storages. Micro grids found popularity over the years due to the needs for distributed generation and with the integration of HRESs including photovoltaic (PV) and wind generators as well as the battery storage devices [3]. Another capability of micro grids is islanding which allows the micro grid to be disconnected from the utility grid in the case of upstream disturbances or voltage fluctuations [2].Hybrid solar PV system has been designed with Wind energy system in MATLAB/SIMULINK so as to enhance its output capacity before its integration with the grid. A suitable controller for the three leg Universal Bridge stabilizer has also been designed such that it produces better output results than the traditional pulse modulation technique. Shivarama Krishna
$\mathrm{K}$ et al. [1] puts forward a comprehensive review of optimal sizing, energy management, operating and control strategies and integration of different renewable energy sources to constitute a hybrid system. The feasibility of the different controllers such as microcontroller, proportional integral controller, hysteresis controller and are presented. Parhizi S. et al. [2] presents a review of issues concerning micro grids and provides an account of research in areas related to micro grids, including distributed generation, micro grid value propositions, applications of power electronics, economic issues, micro grid operation and control, micro grid clusters, and protection and communications issues. Mahmoud Ghofrani et al.[3] discussed fast progression of renewable energy markets, the importance of combining different sources of power into a hybrid renewable energy system (HRES) has gained more attraction. Post $\mathrm{HN}$ et al. [4] in this article examines photovoltaic power system applications, including remote standalone, dispersed grid-connected and large generation centers.

\section{MODELING COMPONENTS}

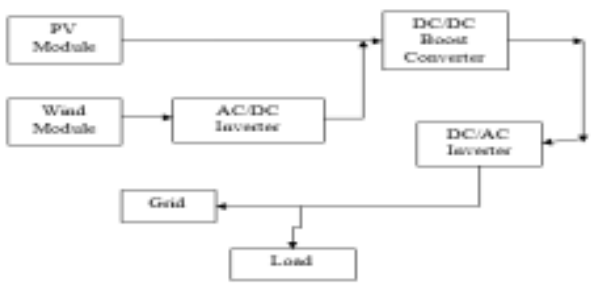

Figure1: Proposed Hybrid energy system topology

1) PV Module modelling:

PV cells have single operating point where the values of the current (I) and voltage (V) of the cell result in a maximum power output. These values correspond to a particular resistance, which is equal to V/I. A simple equivalent circuit of PV cell is shown in Fig. 2. A cell series resistance (Rs) is connected in series with parallel combination 
of cell photocurrent ( $\left.\mathrm{I}_{\mathrm{ph}}\right)$,exponential diode ( D ), and shunt resistance $\left(\mathrm{R}_{\mathrm{sh}}\right)$, cells current $\left(\mathrm{I}_{\mathrm{s}}\right)$ and voltage (Vpv) respectively.

It can be expressed as

$$
I_{p v}=I_{p h}-I_{s}\left(e^{q\left(V_{p v}+I_{p v} * R_{s}\right) / n K T}-1\right)-\frac{V_{p v}+* R_{s}}{R_{s h}}
$$

Where: $I p h$ is Solar-induced current, $I_{S}$ is Diode saturation current, $q$ is Electron charge $\left(1.6 \mathrm{e}^{-19} \mathrm{C}\right), K$ is Boltzmann constant $\left(1.38 \mathrm{e}^{-23} \mathrm{~J} / \mathrm{K}\right), n$ is ideality factor (1 2) and $T$ is Temperature ${ }^{0} \mathrm{~K}$

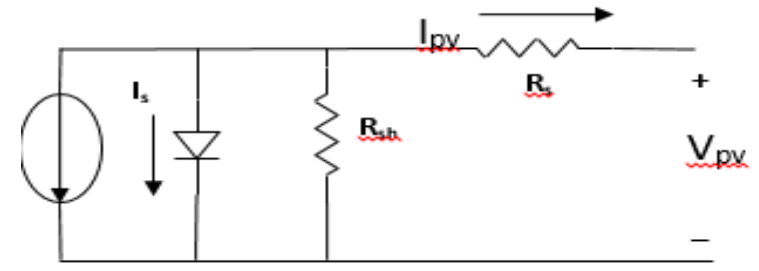

Figure2: Equivalent circuit of solar PV cell

The solar induced current of the solar PV cell depends on the solar irradiation level and the working temperature can be expressed as:

$$
I_{p h}=I_{s c}-k_{i}\left(T_{c}-T_{r}\right) * \frac{I_{r}}{1000}
$$

Where $I_{S C}$ is Short-circuit current of cell at STC $k_{i}$ is Cell short-circuit, $I_{r}$ Irradiance in $\mathrm{w} / \mathrm{m}$ and $\mathrm{Z}_{c}, T_{r}$ Cell working and reference temperature at STC.

A PV cell has an exponential relationship between current and voltage and the maximum power point (MPP) occur at the knee of the curve.

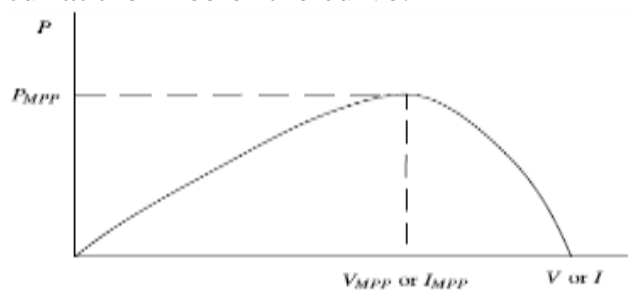

Figure3: Characteristic PV array power curve

\section{Wind energy system modeling:}

Model of wind turbine with PMSG Wind turbines cannot fully capture wind energy. The components of wind turbine have been modelled by the following equations [5].

Output aerodynamic power of the wind-turbine is expressed as:

$$
P_{\text {Turbine }}=\frac{1}{2} \rho A C_{p}(\lambda, \beta) v^{3}
$$

where, $\rho$ is the air density (typically $1.225 \mathrm{~kg} / \mathrm{m} 3$ ), $A$ is the area swept by the rotor blades (in $\mathrm{m}^{2}$ ), $\quad C_{P}$ is the coefficient of power conversion and $v$ is the wind speed (in $\mathrm{m} / \mathrm{s}$ ).

Then Power output is given by

$$
P_{\text {Turbine }} \quad=\frac{1}{2} \rho A C_{p_{\text {max }}} v^{3}
$$

A generic equation is used to model the power coefficient $C_{P}$ based on the modeling turbine characteristics described in [2], [7-9] as:

$$
C_{p}=\frac{1}{2}\left(\frac{116}{\lambda_{i}}-0.4 \beta-5\right) e^{-\left(\frac{21}{\lambda_{i}}\right)}(2.5)
$$

\section{3) Power system modeling:}

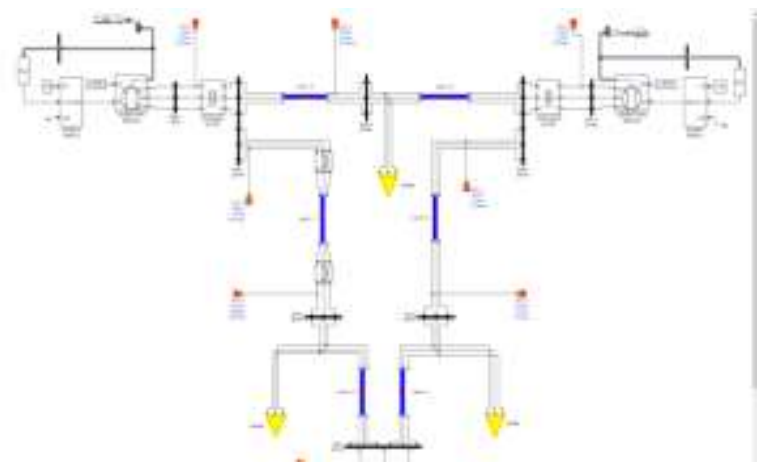

Figure4: Modeled Power system in MATLAB/SIMULINK environment

\section{4) Power System Stabilizer}

Supplementary excitation control of the low frequency oscillations is well known as a power system stabilizer (PSS) [6]. It was developed to aid in damping the electromechanical oscillations via modulation of the generator excitation. Although modern control methods have been used by several researchers to minimize the prescribed objective function, power system utilities still prefer the conventional lead-lag power system stabilizer structure. [7] Since the PSS has attracted the attention of researchers, extensive research has been conducted in the following fields [8-10]:

- $\quad$ Effect of PSS on system stability.

- Optimum PSS location \& number.

- $\quad$ PSS tuning methods.

- PSS input signals.

- Practical experience in design, installation \& operation of PS

There are various control methods through which efficiency and stability of PSS can be achieved, like PI - Hysteresis control, PSO control, PSO with NN control etc. in this paper comparative analysis has been done by these controlling methods.

\section{Optimization and simulation}




\section{1) Power system Stabilizer}

Voltage stabilizer is designed for maintaining the stable voltage level to provide a constant supply in spite of any fluctuations or changes in supply in order to protect loads. Generally voltage regulators are used to maintain constant voltage and these voltage regulators which are used to provide constant voltage to the load. The work stabilizes the output voltage from the hybrid wind energy system.

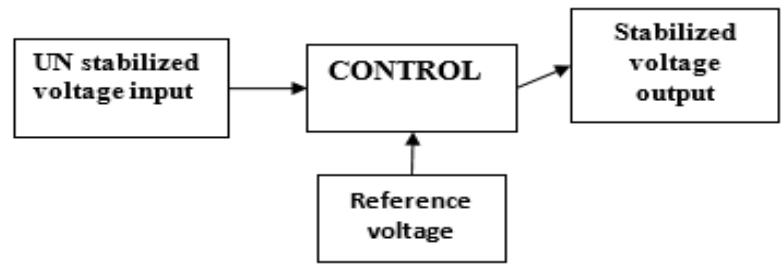

Figure5: Block diagram of PSS working

The paper presents a novel PSO-neural network hybrid power system stabilizer (PSS) design for damping of oscillation and enhancing power system synchronous stability. The hybrid PSS comprises a front-end conventional analog PSS design, a PSO based optimizer and an artificial neural network (ANN) based stabilizer, The work has done a comparative analysis of the three methodologies od PSS being a) PI with hysteresis of PSS b) PSO based control of PSS and c) PSO with neural network control of PSS.

The distortion level in the voltage output from the system by using various types of control of stabilizer before its integration with two system based power system is being analyzed. The comparative analysis of the power system stability is also done by comparing the rotor angle stability of the machines.

Table 1: Comparison of THD in output voltage after using different algorithms

\begin{tabular}{|c|c|}
\hline $\begin{array}{l}\text { Level of THD in voltage output } \\
\text { after various control algorithms }\end{array}$ & $\begin{array}{c}\text { THD (\%) level in voltage } \\
\text { output waveforms }\end{array}$ \\
\hline $\begin{array}{l}\text { THD \% in base system without } \\
\text { stabilizer }\end{array}$ & $5.66 \%$ \\
\hline $\begin{array}{l}\text { THD \% in system with PI and } \\
\text { Hysteresis controlled stabilizer }\end{array}$ & $5.50 \%$ \\
\hline $\begin{array}{l}\text { THD \% in system with PSO } \\
\text { controlled stabilizer }\end{array}$ & $4.24 \%$ \\
\hline $\begin{array}{c}\text { THD \% in system with PSO and } \\
\text { neural network controlled } \\
\text { stabilizer } \\
\end{array}$ & $3.36 \%$ \\
\hline
\end{tabular}

Table above shows the THD level in the voltage output using various algorithms it was concluded that the distortion level in the PSS having PS with neural network control was found to be least. The hybrid system having PSS with PSO with neural network control algorithm is found to be best for voltage quality enhancement and stability improvement as well. The table 2 discusses the various power outputs from the different systems.
Table 2: Comparison of power delivered from hybrid system after using different algorithms

\begin{tabular}{|c|c|}
\hline Various control algorithms & $\begin{array}{c}\text { Approximate Active power } \\
\text { output }\end{array}$ \\
\hline base system without stabilizer & $7.5 \mathrm{KW}$ \\
\hline $\begin{array}{c}\text { system with PI and Hysteresis } \\
\text { controlled stabilizer }\end{array}$ & $7.5 \mathrm{KW}$ \\
\hline $\begin{array}{c}\text { system with PSO controlled } \\
\text { stabilizer }\end{array}$ & $8.7 \mathrm{KW}$ \\
\hline $\begin{array}{c}\text { system with PSO and neural } \\
\text { network controlled stabilizer }\end{array}$ & $9.4 \mathrm{KW}$ \\
\hline
\end{tabular}

The active power output is being depicted in the KW. The table output concludes the efficiency of proposed stabilizer with PSO-NN control. The maximum power output drawn is approximately $9.4 \mathrm{KW}$.

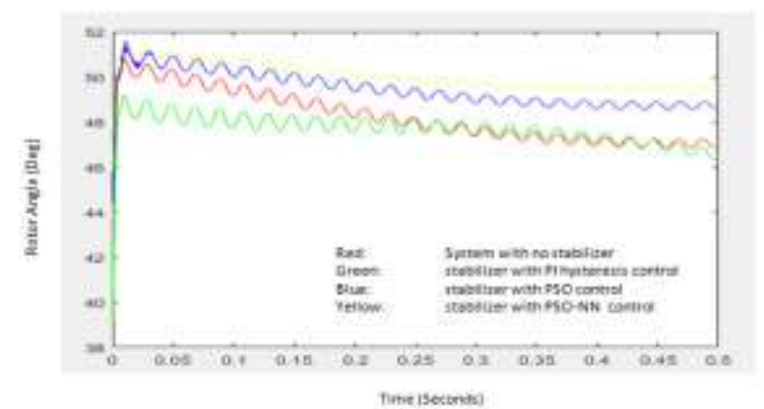

Figure6: Comparative analysis of Rotor angle stability in different cases

Red describes the rotor angle stability in basic system without stabilizer, green describes the rotor angle stability in Stabilizer with PI hysteresis control, blue describes the rotor angle stability in Stabilizer with PSO control, and yellow describes the rotor angle stability in Stabilizer with PSO_NN control.

\section{CONCLUSIONS}

Optimal tuning of power system stabilizer parameters using Optimization based linear control design is carried out. This work provides a comprehensive design and implementation of three-level stabilizer in a hybrid PV Wind Energy system while integrating it with the power system. The basic idea about control for three-legged IGBT based voltage source regulator based stabilizer was discussed in detail. The comparative analysis of the proposed technique in a two machine based model shows its effectiveness and an efficient choice for operation of grid integrated hybrid system. The comparative analysis of the various control algorithms for the stabilization is being carried out. The system has been carried out with basically three algorithms. PI integrated with hysteresis control, Particle swarm optimization (PSO) control, and neural network modified PSO control. THD \% in the system without stabilizer was found to be $5.66 \%$ whereas in the system having particle swarm optimization with neural network based stabilizer 
the distortion level came down to $3.36 \%$. The hybrid system with solar wind energy was further integrated with grid and was analyzed for the rotor angle stability in the machines. It was concluded that out of the three controls for stabilizer, namely PI with hysteresis control, PSO control and PSO with neural network control of stabilizer, the artificial intelligence based PSO with NN was found to be best with maximum stability of machines. The efficiency of system is thus enhanced by making the model better in quality and best in stability. The above conclusions depict the efficiency of the work and hence make the system suitable for driving any kind of loads.

\section{REFERENCES}

[1] K. Shivarama Krishna, Sathish Kumar K. A review on hybrid renewable energy systems. Renewable and Sustainable Energy Reviews 2015; 52: 907-916.

[2] Parhizi S., Lotfi H., Khodaei A., Bahramirad S. State of the art in research on microgrids: a review. IEEE Access 2015; 3: 890-925.

[3] Mahmoud Ghofrani and NegarNiromandHosseini Optimizing Hybrid Renewable Energy Systems: A Review, 2016 intechopenscience

[4] Post HN, Thomas MG. Photovoltaic systems for current and future applications. Sol Energy 1988;41(5):465-73.

[5] Shaahid SM, Elhadidy MA. Opportunities for utilization of stand-alone hybrid (photovoltaic +diesel+ battery) power systems in hot climates. Renew Energy 2003;28(11):1741-53.

[6] Mathew S, Pandey KP, Anil Kumar V. Analysis of wind regimes for energy estimation. Renew Energy 2002;25(3):38199

[7] M. A. Abido, and Y. L. Abdel-Magid, "Optimal design of power system stabilizers using evolutionary programming," IEEE Trans. Energy Con, Vol. 17, No. 4, pp. 429-436, December 2002.

[8] K. E. Bollinger, and S. Z. Ao, "PSS performance as affected by its output limiter," IEEE Trans. Energy Con., Vol. 11, No. 1, pp. 118-124, March 1996.

[9] H. A. Toliyat, and et al., "Design of augmented fuzzy logic power system stabilizers to enhance power systems stability," IEEE Trans. Energy Con., Vol. 11, No. 1, pp. 97-103, March 1996.

[10] K. C. Lee, "Analysis of power system stabilizers application for controlling poorly damped oscillations in the ALCAN/B.C. Hydro power systems," IEEE Trans. Power Sys., Vol. 8, No. 1, pp. 255-263, February 1993. 